\title{
Optimism, volatility and decision-making in stock markets
}

Article

Accepted Version

Creative Commons: Attribution-Noncommercial-No Derivative Works 4.0

Rocciolo, F., Gheno, A. and Brooks, C. (2019) Optimism, volatility and decision-making in stock markets. International Review of Financial Analysis, 66. 101356. ISSN 1057-5219 doi: https://doi.org/10.1016/j.irfa.2019.05.007 Available at https://centaur.reading.ac.uk/84083/

It is advisable to refer to the publisher's version if you intend to cite from the work. See Guidance on citing.

To link to this article DOI: http://dx.doi.org/10.1016/j.irfa.2019.05.007

Publisher: Elsevier

All outputs in CentAUR are protected by Intellectual Property Rights law, including copyright law. Copyright and IPR is retained by the creators or other copyright holders. Terms and conditions for use of this material are defined in the End User Agreement.

\section{www.reading.ac.uk/centaur}

\section{CentAUR}

Central Archive at the University of Reading

Reading's research outputs online 


\title{
Optimism, Volatility and decision-making in Stock Markets ${ }^{\dagger}$
}

\author{
Francesco Rocciolo $^{\mathrm{a}, \mathrm{b}} \quad$ Andrea Gheno ${ }^{\mathrm{b}} \quad$ Chris Brooks $^{\mathrm{a}, *}$ \\ Latest Update: May 29, 2019
}

\begin{abstract}
In this paper we introduce a new, analytically tractable framework for decision-making under risk in which psychological characteristics related to the degree of optimism or pessimism of the decision-maker are considered. The framework we propose, which is based on a two-parameter optimism weighting function, is applicable to a wide range of decision-making models and renders even the simplest, such as expected utility theory, able to describe the behavior of decision-makers within a more parsimonious framework. In particular, the optimism weighting function that we introduce is formalized as a function of the volatility of the lotteries faced. This simplifies applications of the framework to financial decision-making problems. For the purpose of demonstrating this applicability, we also derive an extension to a well-known asset pricing model to elicit a measure of market sentiment in the U.S. stock market. The results lend support to the relevance of the degree of optimism, both in financial decision-making problems and in the expectations that agents have of excess returns in the market.
\end{abstract}

\section{JEL: D81, G12, G41}

Keywords: Optimism, Decision-Making, Financial Markets

\footnotetext{
${ }^{\dagger}$ The authors wish to thank the editor Brian Lucey, an anonymous referee, Mirco Balatti, Giulio Bottazzi, Alfonso Dufour, Darren Duxbury, Sebastiano Della Lena, Ludovico Rossi and participants at the Royal Economic Society and the British Accounting and Finance Association conferences and at a seminar at the ICMA Centre for helpful comments.

*Corresponding Author: ICMA Centre, Henley Business School, University of Reading, Whiteknights, Reading RG6 6BA, UK; C.Brooks@icmacentre.ac.uk
}

${ }^{a}$ ICMA Centre, Henley Business School, University of Reading

${ }^{\mathrm{b}}$ Department of Business Studies, University of Rome III 


\section{Introduction}

The importance of personality and mood in affecting decision-making is now widely documented (see, for example, Hockey et al., 2000; Schwarz, 2000). Although Adam Smith recognized the relevance of this process and was one of the first classical economists to provide psychological explanations of individual behavior (Smith, 1759), financial economists have been slow to incorporate these insights into their models. During the development of neoclassical theory, the economic agent was instead standardized and characterized by a behavior determined according to the strict assumption of rationality. Nobel Prize winner Herbert Simon criticized this limitation and introduced the term "bounded rationality" (Simon, 1957,1991) to emphasize the limits of human rationality and the related sub-optimal problem-solving ability, yet models assuming perfect rationality still abound.

In this paper we focus on decision-making in financial markets and propose a behavioral model following a path that began with expected utility theory (EUT) and continued by original and cumulative prospect theory (PT) introduced by Kahneman and Tversky (1979) and Tversky and Kahneman (1992). According to Fox and Poldrack (2014) amongst others, PT can be considered the leading descriptive paradigm for modeling decision-making under risk and has inspired many other theories as reviewed by Fox et al. (2016), Starmer (2000) and Wu et al. (2004). In general, such theories cannot be used easily and tested with financial market data. The motivation behind our approach is to provide a simple model consistent with $\mathrm{PT}$ that can be applied to financial markets in a straightforward way. We achieve this result by focusing on the degree of optimism of the decision-maker in relation to volatility, a well-known measure that can be estimated simply from price information. In particular, our model differs from the existing literature in that it is a generalization of EUT and PT that explicitly takes into account the optimism of the decision-maker by introducing an optimism weighting function that is tractable and has an explicit connection to financial market data.

The model we introduce relates to two different classes of models in decisionmaking literature that, in different ways, consider optimism in the decision maker's evaluation.

The first class of models is represented by the rank-dependent (RD) theories (Quiggin, 1981; 1982; 1993; Yaari, 1987). In RD theories, as in cumulative PT, a probability weighting function is introduced in order to describe the decision-maker's sensitivity towards the probabilities. In such a framework, a concave and a convex probability weighting function respectively represent optimistic and pessimistic behavior. However, a significant drawback of RD models is that the non-linearity in 
probability resulting from the use of a probability weighting functions, makes applied work more difficult because of the mathematical complexity often required. This has been also reported in Wakker and Deneffe (1996), Abdellaoui (2000), and Bleichrodt and Pinto (2000).

The second class of models that relates our approach attempts to introduce optimism and pessimism through the use of more complex utility functions employed by the decision-makers. Among these, Loomes and Sugden (1982) Regret Theory introduces a regret/rejoice function that quantifies the ex-post utility the DM gets from a choice after the resolution of uncertainty. The optimistic/pessimistic attitude appears in that the final utility reflects apart from the outcomes of the chosen prospect, the outcomes of every other available choice. In this approach, the optimism degree is defined implicitly in the relevance of the regret/rejoice function with respect to the choiceless utility function. Similarly, Gul's (1991) Disappointment Aversion Theory introduces a parameter that weights differently outcomes that are above and below what they called anticipated payoff (certainty equivalent of the prospect). The application of these two approaches to finance results particularly difficult due to two main issues: first both are characterized by a higher mathematical complexity in that each DM uses at least two different utility functions. Second, Disappointment Aversion Theory is characterized by a mathematical circularity in that the representation of preferences is given as implicit. Obviously, this makes tricky the derivation of a closed form solution to asset pricing problems. A last model in this class is by Gollier and Muermann (2010). They introduce a decision criterion under risk that, unlike our model, takes into account utility from anticipatory feelings and disutility from disappointment ex post. Although their criterion is elegant and is applied to a simple theoretical portfolio choice/insurance problem, it is not clear how it would be possible to calibrate it to market data given it's complexity. In particular, subjective probability distributions are here required in order to derive the reference point of the model. In the attempt to use this model in practice one should know the subjective probability distribution of each of the agent as well as a rule of aggregation which collect them in a coherent way. Clearly, from an econometric point of view, these problems are not trivial and easier approaches would be preferable in order to develop applications in finance.

The discussion thus far is summarized in Table 1.

In this paper we follow a different approach to the models cited above, whereby, as in Cenci et. al. (2015), the degree of optimism of the decision-maker is modelled through their attitude towards outcomes above and below the reference point and not necessarily through a probability distortion function. However, differently from them, the optimism weighting function we introduce is very flexible, allows us to avoid 


\begin{tabular}{|c|c|c|c|}
\hline Model & Authors & Address Optimism/Pessimism & Shortcoming \\
\hline Prospect Theory & $\begin{array}{l}\text { Kahneman and } \\
\text { Tversky (1979) }\end{array}$ & Probability Weighting Function & Non-Linear in Probability \\
\hline $\begin{array}{l}\text { Rank Dependent } \\
\text { Utility Theories }\end{array}$ & $\begin{array}{l}\text { Quiggin (1981,1982, } \\
\text { 1993), Yaari (1987) }\end{array}$ & Probability Weighting Function & Non-Linear in Probability \\
\hline Regret Theory & $\begin{array}{l}\text { Loomes and Sugden } \\
\text { (1982) }\end{array}$ & Regret Function & Mathematical Complexity \\
\hline $\begin{array}{l}\text { Disappointment } \\
\text { Aversion Theory }\end{array}$ & Gul (1991) & Disappointment Aversion & $\begin{array}{l}\text { Implicit Representation of } \\
\text { Preferences }\end{array}$ \\
\hline $\begin{array}{l}\text { Gollier and } \\
\text { Meurmann Model }\end{array}$ & $\begin{array}{l}\text { Gollier and } \\
\text { Merumann (2010) }\end{array}$ & $\begin{array}{l}\text { Anticipatory Feelings and } \\
\text { Disappointment Aversion }\end{array}$ & $\begin{array}{l}\text { Subjective Probability } \\
\text { Distribution }\end{array}$ \\
\hline
\end{tabular}

Table 1: Summary of competing decision-making models with shortcomings in their applications in finance

the use of a probability weighting function, and includes a volatility parameter. In particular, we model optimism (pessimism) as the attitude of an agent to focus her attention on possible large positive (negative) outcomes of a lottery and thus, to see in a larger variance a better (worse) opportunity. The assumed connection between the degree of optimism and the volatility of the prospects takes inspiration from recent studies in the financial economics literature. Lee et. al. (2002) show how the sentiment has got an impact on volatilities but does not test the case of reverse causality. Following this intuition, Wang et. al. (2006) show that are volatilities and returns that generate sentiment. Finally, Cao (2017) analyse the effect of beliefs' hereogeneity on the asset price volatility in a dynamic setting.

The remainder of this paper is organized as follows. In Section 2 we derive the model we employ to capture the effect of the degree of optimism on financial decision-making, with its features being illustrated by several examples. Section 3 then proceeds to apply the model in deriving an equilibrium model of asset pricing in which the aggregate level of market optimism affects the prices of assets. Section 4 provides an illustrative empirical calibration of the model to US stock data, while Section 5 concludes. 


\section{The Model}

Let $X=\left\{\left(x_{1}, p_{1}\right) ;\left(x_{2}, p_{2}\right) ; \ldots ;\left(x_{n}, p_{n}\right)\right\}$ be a lottery with $n$ finite outcomes $x_{i}$, each of which has an assigned known probability $p_{i}$, and $\bar{x}$ be the reference point of the decision-maker (henceforth DM) whose utility function $v(x)$ can be expressed in general terms by

$$
v(x)=\left\{\begin{array}{lll}
v_{+}(x, \bar{x}) & \text { if } & x>\bar{x} \\
v_{-}(x, \bar{x}) & \text { if } & x \leq \bar{x}
\end{array}\right.
$$

where $v_{+}(x, \bar{x})$ and $v_{-}(x, \bar{x})$ are the utility functions that characterize the DM's preferences respectively in the domain of gains and of losses with regard to the reference point.

The DM evaluates the lottery $X$ through the following value function $V(X)$

$$
V(X)=\mathbb{E}[v(x)]=\mathbb{E}\left[v_{+}(x, \bar{x})\right]_{+}+\mathbb{E}\left[v_{-}(x, \bar{x})\right]_{-}
$$

where $\left[v_{+}(x, \bar{x})\right]_{+}$and $\left[v_{-}(x, \bar{x})\right]_{-}$are respectively the compact forms of $\max \left(v_{+}(x, \bar{x})\right.$; $\left.v_{+}(\bar{x})\right)$ and $\min \left(v_{-}(x, \bar{x}) ; v_{-}(\bar{x})\right)$ with $v_{+}(\bar{x})=v_{-}(\bar{x})$ being $\bar{x}$, the reference point of the DM. Equation (2) can be rewritten as

$$
V(X)=2\left[\frac{1}{2} \mathbb{E}\left[v_{+}(x, \bar{x})\right]_{+}+\frac{1}{2} \mathbb{E}\left[v_{-}(x, \bar{x})\right]_{-}\right]
$$

The previous equation highlights that, independent of the kind of preferences the DM has, an evaluation criterion based on taking the expectation of the value function in equation (4) equally weights the optimistic (relative gains, i.e. $\max \left[v_{+}(x, \bar{x}) ; v_{+}(\bar{x})\right]$ ) and pessimistic (relative losses, i.e. $\min \left[v_{-}(x, \bar{x}) ; v_{-}(\bar{x})\right]$ ) component of the overall value function. Therefore, in order to properly take into consideration the optimistic/pessimistic behavior of the DM, we replace the equal weights with a weighting function $\phi\left(\gamma, \sigma_{x}\right) \in[0,1]$ :

$$
V_{*}(x)=2\left[\phi\left(\gamma, \sigma_{x}\right) \mathbb{E}\left[v_{+}(x, \bar{x})\right]_{+}+\left[1-\phi\left(\gamma, \sigma_{x}\right)\right] \mathbb{E}\left[v_{-}(x, \bar{x})\right]_{-}\right]
$$

where expectations in the last equation are computed by taking into account the possibility of the employment by the DM of a probability weighting function $w_{i}\left(p_{i}\right)$, as suggested by Tversky and Kahneman (1992) and in many other papers. ${ }^{1}$ Therefore,

\footnotetext{
${ }^{1}$ See for instance Tversky and Fox (1995) and Prelec (1998).
} 
equation (4) can be rewritten as

$$
V_{*}(x)=\sum_{i=1}^{n} v_{*}\left(x_{i}\right) w_{i}\left(p_{i}\right)
$$

where,

$$
v_{*}(x)=\left\{\begin{array}{lll}
v_{*+}(x, \bar{x})=2 \phi\left(\gamma, \sigma_{x}\right) v_{+}(x, \bar{x}) & \text { if } \quad x>\bar{x} \\
v_{*-}(x, \bar{x})=2\left[1-\phi\left(\gamma, \sigma_{x}\right)\right] v_{-}(x, \bar{x}) & \text { if } \quad x \leq \bar{x}
\end{array}\right.
$$

The weighting function $\phi\left(\gamma, \sigma_{x}\right)$, as discussed in section 2.2, depends, by assumption, on the volatility between the lottery outcomes $\sigma_{x}$ through a parameter $\gamma \in[0,1]$. More specifically, according to equation (4), optimistic agents will be characterized by $\phi\left(\gamma, \sigma_{x}\right) \in\left(\frac{1}{2}, 1\right]$ while conversely, pessimistic agents will show $\phi\left(\gamma, \sigma_{x}\right) \in\left[0, \frac{1}{2}\right)$. Coherent with the restrictions on the parameter $\gamma$, the function $\phi\left(\gamma, \sigma_{x}\right)$ is defined in such a way that $\phi\left(\gamma, \sigma_{x}\right) \in\left(\frac{1}{2}, 1\right]$ iff $\gamma \in\left(\frac{1}{2}, 1\right]$ and $\phi\left(\gamma, \sigma_{x}\right) \in\left[0, \frac{1}{2}\right)$ iff $\gamma \in\left[0, \frac{1}{2}\right)$. In this sense, we will refer in this paper to $\phi\left(\gamma, \sigma_{x}\right)$ and $\gamma$ as respectively the optimism weighting function and the degree of optimism parameter.

Use of this technique to model optimism in decision-making is similar in spirit to the subjective beliefs approach which employs subjective expected utility theory as proposed by Savage (1954), and used in, amongst others, Brunnermeier and Parkers (2005). In these models, optimism is included in the evaluation through a distorted measure of probabilities instead of weights applied to gains and losses as we do. Although the two approaches are qualitatively different, it is easy to see that from a mathematical point of view they produce the same results. In fact, from equation (5) we have that the optimism weighting function $\phi\left(\gamma, \sigma_{x}\right)$ can be seen, in expectation, not only as weights applied to monetary outcomes but equivalently as weights applied to probabilities. In this way, the proposed model is perfectly coherent with recognized previous studies in the field. Moreover, our representation of optimism is coherent with other studies in the field which show that optimistic agents, overweight the size of the successful payoffs as well as the probabilities of success, as in De Meza and Southey (1996) and Hillier (1998).

The model described by equations (5) and (6), can be seen as a generalised framework for decision-making in which a wide range of preference types can be formalised through the specification of the reference point $\bar{x}$, the probability weighting function (and thus the weighted probabilities $\left.w_{i}\left(p_{i}\right)\right)$ and the basic value functions $v_{+}(x, \bar{x})$ and $v_{-}(x, \bar{x})$ of the DM. Via this approach, it is possible to extend many of the models known in literature by including the optimism of agents in the specification through the optimism weighting function $\phi\left(\gamma, \sigma_{x}\right)$. The following sections provide an analysis of these four key elements. 


\subsection{Reference point, probability weighting function and value function}

The first component of the generalisation presented in equations (5) and (6) is the reference point $\bar{x}$. In prospect theory, the reference point is defined as a benchmark outcome 'which serves as the zero point of the value scale function' (Kahneman and Tversky, 1979), which means, formally, that $\bar{x}$ is such that $v_{+}(\bar{x})=v_{-}(\bar{x})=0$. By borrowing this definition, in the present context we will refer to gains and losses with respect to the reference point. Hence, according to equation (5), the latter represents a threshold that determines which between the two functions $v_{+}(x, \bar{x})$ and $v_{-}(x, \bar{x})$ is used by the DM to value the outcomes in the prospect faced. In this sense, the choice of reference point in applying the model in equation (5) is a necessary component in order to model widely recognised behavioral features such as loss aversion, or in more general terms, different risk attitudes with respect to gains and losses relative to the benchmark. Standard choices for the reference point in the literature are zero (used for instance in Kahneman and Tversky's original prospect theory (1979), Tversky and Kahneman's cumulative prospect theory (1992) and in Quiggin's rank dependent utility theory $(1981,1982,1993)$ ), the risk-free rate capitalized level of wealth (often used in models which apply non-expected utility models for financial decisions - e.g., Barberis and Huang (2008), Barberis and Xiong (2009) and He and Zhou (2010)) or the expected value of the risky prospect (suggested by Koszegi and Rabin (2006) and Yogo (2005)). Lastly, notice that although the reference point is not relevant in standard expected utility theory in which optimism is not considered, conversely it becomes a crucial component of the decision-making process when it is included in the evaluation. In fact, the employment of the optimism weighting function $\phi\left(\gamma, \sigma_{x}\right)$ gives different weights to values in the domain of gains and losses with respect to the reference point, making the specification of the latter necessary.

Another consolidated feature in the decision-making literature is the attitude of DMs to systematically distort the probability distribution of the prospects they face. This kind of behavior is typically modeled by deriving distorted probabilities through a probability weighting function $w\left(p_{i}\right)$. The latter is a function defined in $[0,1]$ to $[0,1]$, and is non-decreasing, differentiable and such that $w(0)=0$ and $w(1)=1$.

Different specifications of probability weighting functions have been proposed in Tversky and Kahneman (1992), Tversky and Fox (1995) and in Prelec (1998), while numerical estimates of the parameters have been investigated by, amongst others, Wu and Gonzalez (1996) and Abdellaoui (2000).

Lastly, the final ingredients of the generalisation are the value functions $v_{+}(x, \bar{x})$ and $v_{-}(x, \bar{x})$. Following again the framework proposed by Kahneman and Tver- 
sky (1979), these functions act by scaling the monetary outcomes from the gambles through the characteristics of the DM. In this sense, the value functions, and consequently their specifications, contain information on the DM's attitude toward risk and toward losses. By choosing different combinations of the last three elements (the reference point, the probability weighting function and the value function), it is possible to adjust standard decision models such as expected utility and most non-expected utility models known in the literature ${ }^{2}$ (including prospect theory and cumulative prospect theory) by incorporating the optimistic or pessimistic attitude of agents in the decision-making process through the optimism weighting function $\phi\left(\gamma, \sigma_{x}\right)$. The next two examples clarify this feature.

\section{Example 1 [Expected Utility Theory Specification]}

Given equation (6), optimism-adjusted expected utility theory is obtained by taking zero as the reference point and by considering a strictly concave Von NeumannMorgenstern (henceforth VNM) utility function $u(x)$ which is applied in both gain and loss domains. Formally, equation (6) reverts to EUT if $\bar{x}=0$ and $v_{+}(x)=$ $v_{-}(x)=u(x)$ and hence the resulting optimism-adjusted EUT model is

$$
v_{*}(x)=\left\{\begin{array}{lll}
2 \phi\left(\gamma, \sigma_{x}\right) u(x) & \text { if } & x>0 \\
2\left[1-\phi\left(\gamma, \sigma_{x}\right)\right] u(x) & \text { if } & x \leq 0
\end{array}\right.
$$

where $u(x)$ can be further parametrized in terms of a canonical functional form depending on the risk attitude of the DM. Furthermore, in standard EUT, DMs do not weight the probability distribution of the lottery so that, in equation (5), $w\left(p_{i}\right)=p_{i}$.

\section{Example 2 [Exponential VNM Utility Function Specification]}

A particular degenerate case of the specification in the previous example is represented by the use of a negative exponential utility function of the type

$$
u(x)=-\exp (-a x)
$$

where $a$ is the Arrow-Pratt absolute risk aversion coefficient. The latter, which represents a class of constant absolute risk aversion (CARA) utility functions, plays a particularly important role in economics, being widely used in both economic and

\footnotetext{
${ }^{2}$ The exceptions are time-varying, stochastic and recursive utility models such as Epstein and Zin (1989) and Duffie and Epstein (1992) where the adjustment cannot be applied.
} 
financial applications. ${ }^{3}$ In this peculiar case the function $u(x)$ is defined in $\mathbb{R} \rightarrow \mathbb{R}^{-}$ so that, for a generic reference point $\bar{x}$, equation (4) becomes

$$
V_{*}(x)=2\left[\phi\left(\gamma, \sigma_{x}\right) \mathbb{E}[\max (u(x) ; u(\bar{x}))]+\left[1-\phi\left(\gamma, \sigma_{x}\right)\right] \mathbb{E}[\min (u(x) ; u(\bar{x}))]\right]
$$

Since by definition $u(\bar{x})=0$, the previous equation can be rewritten as

$$
V_{*}(x)=2\left[\phi\left(\gamma, \sigma_{x}\right) \mathbb{E}[\max (u(x) ; 0)]+\left[1-\phi\left(\gamma, \sigma_{x}\right)\right] \mathbb{E}[\min (u(x) ; 0]]\right.
$$

where $\mathbb{E}[\max (u(x) ; 0)]=0$ because $u(x)$ only admits negative values, and thus

$$
v_{*}(x)=-2\left[1-\phi\left(\gamma, \sigma_{x}\right)\right] \exp (-a x)
$$

\section{Example 3 [Cumulative Prospect Theory Specification]}

The cumulative version of prospect theory (CPT) can be obtained by again taking zero as the reference point and by considering a strictly concave function $v_{+}(x)$ which is applied in the gains domain and a different function $v_{-}(x)$ which is conversely strictly convex in the losses domain. Recall that this kind of distinction is representative of the loss aversion of the DM. Formally, if in equation (6) we set $\bar{x}=0$ and, by using the same parametrization of Tversky and Kahneman (1992), we also set $v_{+}(x)=x^{\alpha}$ and $v_{-}(x)=(-k)(-x)^{\beta}$ then we obtain CPT. Hence the resulting optimism-adjusted $\mathrm{CPT}$ model is

$$
v_{*}(x)=\left\{\begin{array}{lll}
2 \phi\left(\gamma, \sigma_{x}\right) x^{\alpha} & \text { if } & x>0 \\
2\left[1-\phi\left(\gamma, \sigma_{x}\right)\right](-k)(-x)^{\beta} & \text { if } & x \leq 0
\end{array}\right.
$$

where $\alpha$ and $\beta$ are the parameters which control the risk aversion showed by the DM respectively in the domains of gains and losses and $k$ is the quantification of loss aversion. To complete the specification, in equation (5) the weighted probability $w\left(p_{i}\right)$ takes the form in (7).

\footnotetext{
${ }^{3}$ Some celebrated applications are models for pricing in equilibrium (see, for instance, Grossman (1976), Grossman and Stiglitz (1980) and Kyle (1985,1989)), models for consumption (such as Caballero (1990) and Wang (1993)) or the consumption based Capital Asset Pricing Model specification (Cochrane (2001)).
} 


\subsection{Optimism weighting function}

In the model described in equation (6), utilities from gains and losses are weighted differently through the optimism function $\phi\left(\gamma, \sigma_{x}\right)$. In order to elicit such a function and to support an application of this model to financial decision making problems, we need to provide a more precise definition of what optimism means in a framework in which a DM is facing complicated lotteries such as stocks.

We can think of optimism as the attitude of an agent to focus her attention on possible large positive outcomes of the stock's returns and conversely of pessimism as the attitude of concentrating on extreme negative outcomes. A possible way in which this attitude can be modeled is by applying weights, that are themselves function of parameters that measure the range in which the outcomes are defined, respectively to gains and losses relative to the reference point. The breadth of stock outcomes is clearly well represented by the variance around the expected return so that we can conjecture a weighting function of gains $\phi\left(\gamma, \sigma_{x}\right) \in[0,1]$ that for an optimist $\left(\gamma \in\left(\frac{1}{2}, 1\right]\right)$ monotonically increases up to 1 when the variance increases and for a pessimist $\left(\gamma \in\left[0, \frac{1}{2}\right)\right)$ monotonically decreases to zero when the variance increases. A possible function of this type is the following

$$
\phi\left(\gamma, \sigma_{x}\right)= \begin{cases}1-\frac{1}{2} \exp \left\{-a\left(\gamma-\frac{1}{2}\right) \sigma_{x}^{2}\right\} & \text { if } \quad \frac{1}{2} \leq \gamma<1 \\ \mathbb{1}_{\sigma_{x}^{2}<\sigma_{*}^{2}}\left[1-\frac{1}{2} \exp \left\{-a\left(\gamma-\frac{1}{2}\right) \sigma_{x}^{2}\right\}\right] & \text { if } \quad 0<\gamma<\frac{1}{2}\end{cases}
$$

where $\mathbb{1}_{\sigma_{x}^{2}<\sigma_{*}^{2}}$ is an indicator function which is equal to 1 iff $\sigma_{x}^{2}<\sigma_{*}^{2}$ and to 0 otherwise and where $\sigma_{*}^{2}=\frac{\log (2)}{a(1 / 2-\gamma)}$.

The level of variance $\sigma_{*}^{2}$ can be interpreted as the maximum tolerable level of variance for a pessimistic agent characterized by an absolute risk aversion $a$ and a given degree of optimism $\gamma$. The latter, which formally represents a technical assumption for avoiding situations in which DMs weight negatively the gains and positively the losses, actually has a clear, intuitive interpretation. Consider for instance a pessimistic DM who faces a binary choice problem with both positive and negative outcomes. Intuitively, the greater the variance between the outcomes of the two prospects, the more she will focus her attention on the negative eventualities and thus the more weight she will assign to the losses compared with gains. In this sense, when the variance exceeds a certain level we can expect that she will consider only the losses in the analysis. Moreover, we can expect that the greater is the risk aversion, the lower is the maximum tolerable variance level. This explains the resulting 
negative dependence between $\sigma_{*}^{2}$ and the level of absolute risk aversion $a$. Moreover, it can easily be shown that, for $\sigma_{x}^{2} \geq\left(-\sigma_{*}^{2}\right)$, optimistic DMs will show $\phi\left(\gamma, \sigma_{x}\right)=1$ and will end up considering only gains in their evaluation.
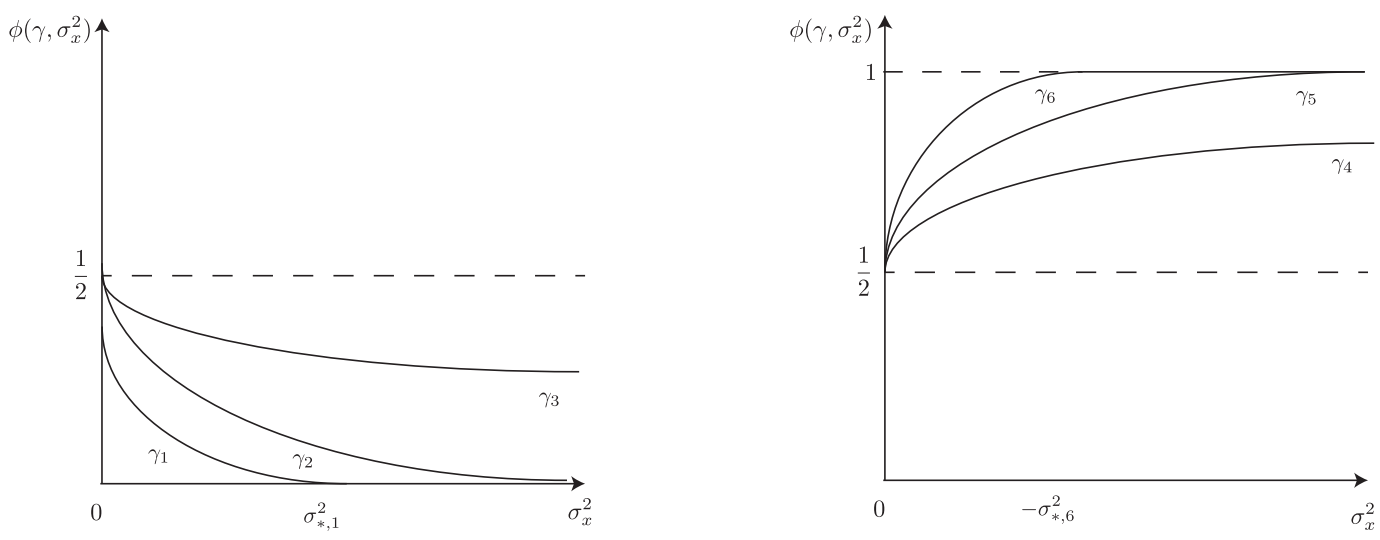

Figure 1: Representation of the function $\phi\left(\gamma, \sigma_{x}\right)$ for different levels of variance and a given level of risk aversion. The left-hand plot represents the optimism weighting function for different levels of the degree of optimism $\gamma \in(0,0.5), \gamma_{1}<\gamma_{2}<\gamma_{3}<0.5$. Conversely, the right-hand plot represents the optimism weighting function for different levels of $\gamma \in$ $(0.5,1), \gamma_{6}>\gamma_{5}>\gamma_{4}>0.5$.

\subsection{Optimism, risk attitude and loss aversion}

According to equation (6), optimism takes form in the model as a weight applied to the value function. A possible issue that may arise is if the optimism weighting function is just a proxy for the DM's attitude toward risk and/or losses.

In order to make clear the link between the degree of optimism, risk attitude and loss aversion, we propose three examples in which a DM with certain characteristics has to choose between two prospects. Let us consider a DM whose preferences are represented by a CARA VNM utility function of the type $1-\exp \left\{-x_{i}\right\}$, where for simplicity a unitary risk aversion coefficient is assumed.

The following three examples (numbered 4 to 6 ) involve two different kinds of lotteries. The first type, used in both Examples 4 and 6, are lotteries which are characterized by non-negative or non-positive outcomes. We will refer to this type of lottery as respectively positively and negatively skewed. The second type, used in 
Example 5, is instead characterized by mixed positive and negative outcomes. We will refer to this as a non-skewed lottery. This distinction between these two types of gamble is crucial in order to correctly interpret the results elicited later in the paper.

The first example is the very widely known Allais' counterexample of EUT (Allais, 1953). We show that under likely conditions, in the model we propose, the expected utility theory can be adjusted in such a way that it is able to predict the empirical evidence collected in the seminal paper of Allais cited above and many others including Kahneman and Tversky (1979) and, more recently, Birnbaum (2008).

\section{Example 4 [The Allais Paradox]}

Table 2 below shows two choice problems labeled E1 and E2 in which the DM has to choose between problem A and B in E1 and between C and D in E2.

\begin{tabular}{ccccccccc}
\hline & \multicolumn{4}{c}{$\mathrm{E} 1$} & \multicolumn{4}{c}{$\mathrm{E} 2$} \\
\hline & $\mathrm{A}$ & \multicolumn{2}{c}{$\mathrm{B}$} & \multicolumn{2}{c}{$\mathrm{C}$} & \multicolumn{2}{c}{$\mathrm{D}$} \\
& $x_{i}$ & $p_{i}$ & $x_{i}$ & $p_{i}$ & $x_{i}$ & $p_{i}$ & $x_{i}$ & $p_{i}$ \\
\hline & & & 500 & 0.1 & 100 & 0.11 & 500 & 0.1 \\
& 100 & 1 & 100 & 0.89 & 0 & 0.89 & 0 & 0.9 \\
& & & 0 & 0.01 & & & & \\
\hline $\mathbb{E}[x]$ & 100 & \multicolumn{2}{c}{139} & & 11 & & 50 \\
$\sigma_{x}^{2}$ & 0 & & 14579 & & 979 & & 22500
\end{tabular}

Table 2: Allais counterexample to EUT (1953), where $x_{i}$ are the monetary outcomes expressed in million and $p_{i}$ are the corresponding probabilities.

The empirical evidence cited above shows that the majority of DMs prefer A to $\mathrm{B}$ and $\mathrm{D}$ to $\mathrm{C}$, and that leads to the famous critique of Allais that such a preference ordering is not obtainable through EUT. If the DM is endowed with the preferences described in equation (6) and with a CARA basic utility function, we have that for the problem E1, she would choose opportunity A if

$$
\phi_{A} v(100)>\phi_{B}[v(500) 0.1+v(100) 0.89] \leftrightarrow \phi_{B} \leq \frac{0.5 v(100)}{v(500) 0.1+v(100) 0.89}=0.5005
$$

being $\sigma_{A}^{2}=0$ and so $\phi_{A}=0.5$, which means that a DM with these preferences chooses A if endowed with a degree of optimism $\gamma<0.5005$ - i.e., if she is pessimistic or slightly optimistic.

In the same way, for E2 the DM chooses D iff 


$$
\phi_{C}[v(100) 0.11]<\phi_{D}[v(500) 0.1] \leftrightarrow \phi_{D}>\phi_{C} \frac{0.11}{0.1}
$$

For the given levels of variance showed by the two lotteries, a DM with these preferences will choose lottery $\mathrm{D}$ for any value of the degree of optimism parameter so that the Allais paradox is explained for $\gamma \in[0,0.5005]$.

The resulting $\gamma$ fits reality well if we think that the sample of DMs is Gaussian in terms of their degree of optimism. In this case, in fact, we have that almost all DMs in the sample will have a degree of optimism close to 0.5 and values a considerable distance from the mean will have very low frequency.

A possible issue that arises when applying this model to the previous example is that one may suspect optimistic DMs to necessarily be risk lovers. This is a possibility that would actually only arise when choice problems that involve positively skewed lotteries are considered. The next example clarifies the relationship between optimists and risk seeking DMs when standard lotteries with both positive and negative outcomes are considered.

\section{Example 5 [Does optimism imply a love for risk?]}

In this choice problem, alternatives $\mathrm{E}$ and $\mathrm{F}$ share the same expected value and differently from Example 1, the risky lottery $\mathrm{F}$ implies a non-null probability of losing money.

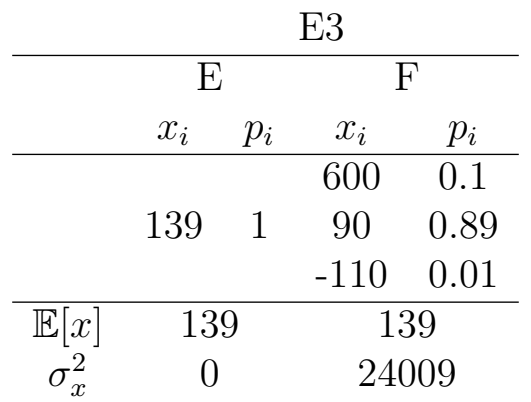

Table 3: Example of a non skewed lottery evaluation.

By applying the same model used in Example 4, we have that the CARA DM prefers variance and chooses opportunity $\mathrm{F}$ if and only if

$$
v(139)<2 \phi_{F}[v(600) 0.1+v(90) 0.89]+2\left(1-\phi_{F}\right) v(-110) 0.01 \leftrightarrow
$$




$$
\leftrightarrow \phi_{F}>\frac{0.5 v(139)-v(-110) 0.01}{v(600) 0.1+v(90) 0.89-v(-110) 0.01}=1
$$

Hence, a possible optimism level such that a risk averse agent will prefer the risky lottery to the certain outcome does not exist.

\section{Example 6 [Optimism and loss aversion]}

This last choice problem, taken from Kahnemann and Tversky (1979), allows us to verify whether the proposed model is able to catch the widely recognized concept of loss aversion of DMs and at the same time whether the optimism weighting function is merely a proxy for it. The choice problem involves a certain loss and a negatively skewed lottery and is represented in Table 4.

\begin{tabular}{|c|c|c|c|c|c|c|c|c|}
\hline & \multicolumn{4}{|c|}{$\mathrm{E} 4$} & \multicolumn{4}{|c|}{ E5 } \\
\hline & \multicolumn{2}{|l|}{ G } & \multicolumn{2}{|c|}{$\mathrm{H}$} & \multicolumn{2}{|l|}{$\mathrm{I}$} & \multicolumn{2}{|c|}{$\mathrm{L}$} \\
\hline & $x_{i}$ & $p_{i}$ & $x_{i}$ & $p_{i}$ & $x_{i}$ & $p_{i}$ & $x_{i}$ & $p_{i}$ \\
\hline & 3000 & 1 & 4000 & 0.8 & -3000 & 1 & -4000 & 0.8 \\
\hline & & & 0 & 0.2 & & & 0 & 0.2 \\
\hline $\mathbb{E}[x]$ & 3000 & & 32 & & -3000 & & -32 & \\
\hline$\sigma_{x}^{2}$ & 0 & & 2.56 & $10^{6}$ & 0 & & 2.56 & $0^{6}$ \\
\hline
\end{tabular}

Table 4: Kahneman and Tversky (1979) example of the reflection effect.

Through this example, Kahnemann and Tversky show that $80 \%$ of the people they surveyed prefer $\mathrm{G}$ to $\mathrm{H}$ and almost all of them L to I, i.e. they prefer certainty over risk if the lottery is positively skewed and conversely risk over certainty if the lottery is negatively skewed. They call this phenomenon a reflection effect and show that it constitutes another violation of EUT.

According to our model, a basic risk averse DM with CARA preferences chooses opportunity G for $\gamma<0.61$ and lottery L for $\gamma>0.75$. Hence, the paradox cannot be explained by this model alone, and thus we can conclude that the degree of optimism is not just a proxy for loss aversion, which is still necessary in order to model the behavior of agents with respect to losses.

The situation in the three examples presented is summarized in Figure 2, in which the utility function of DMs and their indifferences curves in the three situations are depicted. Figure 2 shows on the left the steepening or flattening effect in the utility function due to the degree of optimism of the DM. On the right side, the situation in Example 4 is depicted. By recalling that Example 4 considers a positively skewed 
choice problem, we have as a result that an "inner" risk averse DM may turn riskseeking if sufficiently optimistic and hence may show concave indifference curves. In the same way, when we consider a negatively skewed lottery as in Example 6, a highly optimistic DM may turn risk-seeking in the domain of losses as showed in the right side lower plot. Lastly, the left side lower plot shows the situation in which non-skewed lotteries are considered. We notice that in these cases the risk attitude of the DM holds for every value of $\gamma$.
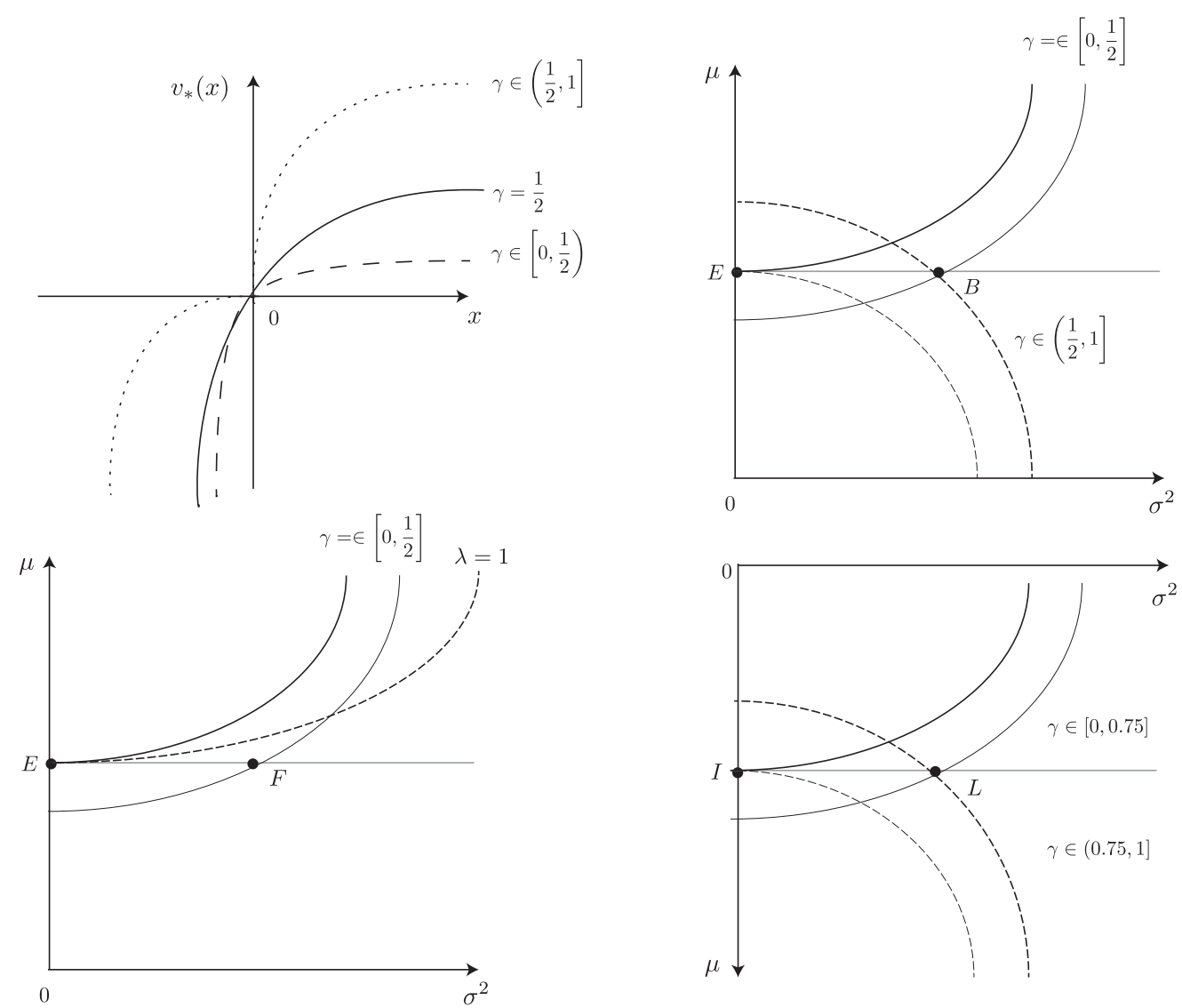

Figure 2: Exponential utility function and corresponding indifference curves in Examples 4,5 and 6 .

The three examples above show the presence of two types of attitude towards risk in the evaluation. The first one, which is implicitly defined in the form of the 
value function and that represents a sort of general (global, intrinsic) attitude, and a second one which, ceteris paribus, is situation-specific (i.e., lottery-dependent). In what follows, we will refer to the first one as the inner risk attitude and to the second as the outer risk attitude. Inner risk attitude can be appropriately measured through the Arrow-Pratt coefficient of absolute risk aversion which, in terms of equation (6), can be defined as

$$
a=\left\{\begin{array}{lll}
a_{+}=-\frac{v_{*+}^{\prime \prime}(x, \bar{x})}{v_{*+}^{\prime}(x, \bar{x})} & \text { if } \quad x>\bar{x} \\
a_{-}=-\frac{v_{*-}^{\prime \prime}(x, \bar{x})}{v_{*-}^{\prime}(x, \bar{x})} & \text { if } & x \leq \bar{x}
\end{array}\right.
$$

Proposition 1 A DM with preferences represented by equation (6) is said to be, with respect to the domain of gains, inner risk averse if $a_{+}>0$, risk neutral if $a_{+}=0$ and risk seeking if $a_{+}<0$. The same applies to the domain of losses with respect to $a_{-}$.

As Examples 4 and 6 show, the inner and outer risk attitudes do not necessarily coincide. This sort of non-coherence by DMs in special conditions such as when they face a skewed lottery, and which may seem a schizophrenic type of behavior, has recently become a topic of considerable interest in the decision-making literature. ${ }^{4}$ Moreover, this kind of extraordinary situation in which DMs face skewed lotteries happens very infrequently (as an analogy, consider how many times during their lifetime an agent can get involved in TV shows which offer free money in a game) while non-skewed lotteries represent the standard context (for instance, situations in which the agent buys a lottery ticket or a stock). As a result, from equation (6) we have the following theorem.

Theorem 1 In reference to a risky lottery $X$, a DM who has preferences described by equation (6) and an inner risk attitude defined by equation (8) acts as risk averse if,

$$
\phi_{x}<\frac{\frac{1}{2} v(\mu)-V_{-}(X)}{V_{+}(X)-V_{-}(X)},
$$

risk neutral if

$$
\phi_{x}=\frac{\frac{1}{2} v(\mu)-V_{-}(X)}{V_{+}(X)-V_{-}(X)}
$$

\footnotetext{
${ }^{4}$ See, for instance, Garret and Sobel (1999) or Grossman and Heckel (2015).
} 
and risk seeking if

$$
\phi_{x}>\frac{\frac{1}{2} v(\mu)-V_{-}(X)}{V_{+}(X)-V_{-}(X)},
$$

where $\mu$ is the expected value of the lottery and where $V_{+}(X)$ and $V_{-}(X)$ are respectively the expected utilities of the positive and negative outcomes of the gamble.

At the same time, Example 5 shows that in normal circumstances in which the DM faces a non-skewed choice problem as in Example 5, we notice that inner risk aversion holds, at least for relevant monetary outcomes. In order to model this feature formally, let $M$ be a sufficiently large generic monetary amount in a choice problem $X$ with $n$ possible outcomes, so that the possible loss of $M$ or of a larger amount does have a significant impact on the DM in terms of perceived utility. The prospect $X$ can be reformalized by splitting the $m$ positive outcomes and the $n-m$ negative outcomes as follows $X=\left\{\left(x_{1}, p_{1}\right) ; \ldots ;\left(x_{m}, p_{m}\right)+\left(\left(x_{m+1}, p_{m+1}\right) ; \ldots ;\left(x_{n}, p_{n}\right)\right)\right\}$ where the latter take place in the prospect $X$ in terms of absolute values. According to this representation of lottery $X$, it makes sense to revise the value function as well by assuming in equation (6) that $v_{-}(x)=v_{-}(-x)$. Notice that this representation, given the new formalization of $X$, is perfectly equivalent to the standard one. From Theorem 1, we have the following corollary as a result.

Corollary 1 Let $X=\left\{\left(x_{1}, p_{1}\right) ; \ldots ;\left(x_{m}, p_{m}\right)+\left(\left(x_{m+1}, p_{m+1}\right) ; \ldots ;\left(x_{n}, p_{n}\right)\right)\right\}$ be a nonskewed lottery and $v_{+}(x)=v_{-}(x)=v(x)$ be a strictly concave VNM utility function. From theorem 1 we have that

$$
\lim _{x_{i} \rightarrow M} \frac{\frac{1}{2} v(\mu)-V_{-}(X)}{V_{+}(X)-V_{-}(X)}=\lim _{x_{i} \rightarrow M} \frac{-V_{-}(X)}{-V_{-}(X)}=1,
$$

Hence, the inner risk attitude of the DM with such preferences holds regardless of the prospect outcome-probability structure faced.

\section{A Constant Absolute Risk Aversion Model}

In this section, we apply the model presented above in order to derive a behavioral version of a simple model for asset pricing in equilibrium in which market optimism is implicitly considered as a determinant of assets prices. In what follows, we will use as a framework the economy assumed by Grossman (1976) and Grossman and Stiglitz (1980) and extend the basic model to the presence of different degrees of optimism. 
Let us consider a simplified one-period economy with a finite population of $n$ agents in which only two securities are traded: a riskless asset which makes a certain gross interest rate $r \geq 1$ and a risky one which pays a random payoff $\tilde{v}$, normally distributed with mean $\mu_{v}$ and variance $\sigma_{v}^{2}$. Let $p$ be the price of the risky asset at time $t=0$ and assume the price of the riskless security to be normalized to 1 .

The agent $i$ is initially endowed with a portfolio $\left(m_{i}, z_{i}\right)$ of the two assets such that her initial level of wealth $w_{0}^{i}$ will be equal to $w_{i}^{0}=p z_{i}+m_{i}$. Given $w_{i}^{0}$, the agent will select her optimal portfolio of the two assets $\left(b_{i}, x_{i}\right)$ by maximising the utility of her final level of wealth $w_{i}=\left(m_{i}+p z_{i}\right) r+x_{i}(\tilde{v}-p r)$ which is also a normally distributed random variable with mean $\mu_{w}=\left(m_{i}+p z_{i}\right) r+x_{i}\left(\mu_{v}-p r\right)$ and variance $\sigma_{w}^{2}=\sigma_{v}^{2} x_{i}^{2}$. We also assume:

ASSUMPTION 1: Every agent $i$ is equipped with a CARA basis utility function of the type $v_{+}(x)=v_{-}(x)=-\exp \left\{-a_{i} w_{i}\right\}$ so that her adjusted value function will be

$$
v_{*}\left(w_{i}\right)=-2\left[1-\phi\left(\gamma_{i}, \sigma_{w}\right)\right]\left[\exp \left\{-a_{i} w_{i}\right\}\right]
$$

Notice that, as in Example 2, in equation (9) $u(x)$ is a function defined in $\mathbb{R}$ to $\mathbb{R}^{-}$so that the maximum component of the overall value function in equation (4) is equal to zero.

ASSUMPTION 2: Agents all employ the same probability measure, i.e. $w_{i, j}\left(p_{i, j}\right)=$ $p_{i, j}$ for all outcomes $j$ and for every agent $i$.

ASSUMPTION 3: Optimism weighting functions $\phi\left(\gamma_{i}, \sigma_{w}\right)$ take the form in (8).

ASSUMPTION 4: There exists an exogenous supply $z_{0}$ of the risky asset. The aggregate supply is hence given by

$$
\sum_{i=1}^{n} z_{i}+z_{0}
$$

ASSUMPTION 5: There are no trading frictions or constraints, short sales are admitted but agents cannot over-spend their initial level of wealth.

ASSUMPTION 6: Market clearing.

$$
\sum_{i=1}^{n} x_{i}(p)=\sum_{i=1}^{n} z_{i}+z_{0}
$$


where $x_{i}(p)$ is the risky asset demand schedule for agent $i$.

ASSUMPTION 7: For every level of variance $\sigma_{w}^{2}>\sigma_{*, i}^{2}$, the demand for the risky asset of agent $i$ tends to zero.

\subsection{Competitive equilibrium with symmetric information}

Under assumptions (1) to (6), every agent $i$ will determine, at time $t=0$, her demand schedule for the risky asset by solving the following optimization

$$
\max _{x_{i}(p)} \mathbb{E}\left[v_{*}\left(w_{i}\right)\right]
$$

subject to the following budget constraint

$$
p x_{i}+b_{i}=p z_{i}+m_{i}
$$

Proposition 2 Under assumptions (1) to (6), in a competitive one period economy under symmetric information, the individual demand schedule for the risky asset is given by

$$
x_{i}=\frac{\mu_{v}-p r}{\sigma_{v}^{2}\left(a_{i}-2 \gamma_{i}+1\right)}
$$

The corresponding equilibrium price of the risky asset will be equal to

$$
p=\frac{1}{r}\left(\mu_{v}-\frac{z \sigma_{v}^{2}}{\bar{\tau}}\right)
$$

where $\bar{\tau}=\frac{1}{n} \sum_{i=1}^{n} \frac{1}{a_{i}-2 \gamma_{i}+1}$ is the average outer risk tolerance, i.e. the average risk tolerance adjusted for the average degree of optimism and $z=\frac{1}{n}\left(\sum_{i=1}^{n} z_{i}+z_{0}\right)$ is the average per capita endowment of the risky asset.

Before analyzing the market's degree of optimism, there are some features of the equilibrium price $p$ and individual optimal share holding $x_{i}(p)$ in (15) and (16) that are worth noting. As in the standard framework in which the degree of optimism is not considered, the optimal share holding does not depend, at least in this first instance, on the initial endowment of the agent and results as an increasing linear function of the expected excess return and decreasing with respect to the risk aversion and intrinsic risk of the asset. In particular, the absolute risk aversion acts as a diffusion coefficient of the variance and determines how much a higher risk will 
reduce demand for the stock. However, in this framework the latter effect is filtered by the degree of optimism of the agent in such a way that higher risk will reduce the optimal share holding less (if optimistic) or more (if pessimistic). The resulting demand schedule as a function of the risky payoff variance is depicted in Figure 3 for different levels of the degree of optimism.

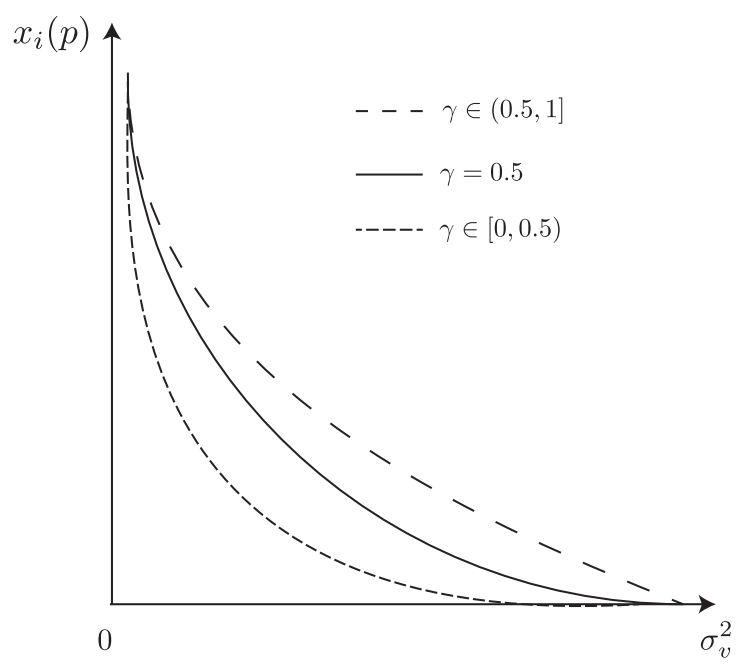

Figure 3: Demand for the risky asset function for different levels of the degree of optimism.

Moreover, we notice that, ceteris paribus, significant differences in demand due to different degrees of optimism between agents are perceivable only for certain normal levels of variance. This is coherent with the observation we pointed out in the comparison between optimism and risk aversion. In fact, here it is clear that optimism does not imply a love for variance and more specifically, an abnormal level of variance would mean no participation in the stock market independently of how optimistic agents are. This reflects the intuition that the more agents are optimistic the more they tend to be involved in the stock market and the more the price rises due to pressure on demand. Conversely, the more agents are pessimistic, the more we can imagine that they will stay away from the market and thus they will reduce the price due to increased pressure on the supply side.

Regarding the equilibrium price, as for the demand schedule, the function results in an increase in the expected return with an adjustment due to the payoff's variance and inner risk aversion. Again, the effect of adding optimism to the analysis is a filtration on how agents perceive the intrinsic risk of the priced asset. 


\section{Eliciting the degree of optimism from the US stock market}

In this section, we employ the model derived above in a very simple calibration exercise for the purpose of eliciting a measure of the degree of optimism in the US stock market over different periods. In order to do this, we consider traders in the market as agents who act in a Markovitz economy, so that every agent will hold a portfolio composed of different combinations of only the market portfolio and the risk free asset.

By defining the expected risk premium as $q=\left(\mu_{v}-p r\right) / \sigma_{v}^{2}$, equation (15) can be rewritten as

$$
q=\frac{z}{\bar{\tau}}
$$

which can be used in our exercise by implementing a simple 1-year rolling-window time-series regression model of the type

$$
\hat{q}_{t, g}=\alpha_{g}+\hat{z}_{t, g} \beta_{g}+\varepsilon_{g}
$$

where $\hat{q}_{t, g}$ is a proxy for the expected excess returns, $\hat{z}_{t, g}$ is a proxy for the average per capita endowment of the risky asset, $\beta_{g}$ are the regressions' coefficients, $\alpha_{g}$ are the intercepts and $g$ denotes the year referred to.

Our main dataset concerns the daily realized risk premia for the period 2012-2016, downloaded from Bloomberg and computed as the difference between the day-to-day returns on the ETF SPY50 Equity, which we may consider as the mimicking portfolio for the market, and the day-to-day returns on the 30-day T-Bill, a proxy for the risk free rate, divided by the daily historical variance of the former. As a proxy for the average per capita endowment, $z_{t, g}$, we employ the volume weighted average price (VWAP) ask volume percentage. This is a measure of the percentage of trades that happen on the ask side, and is therefore a measure of $z_{t, g}$. In order to derive the model-calibrated degree of optimism coefficients, we have set the average absolute risk aversion coefficient $\bar{a}$ equal to different values in the range $[0.5,1.5]$. This choice takes into account previous studies in the field, such as Mehra and Prescott (1985), who state that the absolute level of risk aversion of a representative agent should be constant over time and approximately equal to one. Notice that the constancy over time of absolute risk aversion is implicitly assumed in our model through the use of a CARA utility function as in equation (9).

Table 5 summarizes the results relative to the regressions in equation (17) and the 
corresponding degree of optimism coefficient estimates. The betas are significantly different from zero for every year at a significance level of $10 \%$ or better, so that the aggregate degree of optimism is given a strong motivation as potentially relevant in the explanation of US stock market risk premia. In the absence of a correction for optimism, in order to explain the observed level of the risk premium, the absolute risk aversion coefficient would need to vary significantly over time and sometimes to assume values not admitted in the literature (for instance, in 2016, the equity risk premium results explained just for a risk aversion approximately null). In this sense, considering only risk aversion as an explanatory variable for the risk premium seems insufficient, both because the calibration results might be out of the admissible range and since they would violate the assumption of a long-term, constant level of risk aversion. Conversely, the introduction of the degree of optimism in the model allows the latter to explain historical risk premia by assuming risk aversion to be constant and equal to a plausible level. With regard to the results in Table 5, by observing the calibrated relative degree of optimism parameter, computed as $\rho_{a}=\gamma_{a} / a$, the results seem robust with respect to the selected levels of risk aversion for the sample analyzed. Furthermore, as we may notice, in both Table 5 and Figure 4, the historical trend in the coefficients, computed by varying the level of average risk aversion, seems tied to important socio-economic and political events that happened in the US over the period, such as the 2013 fiscal cliff, in which we may have expected a drop in the average degree of optimism (and our analysis confirms that) and Trump's election in 2016 (which appears to have made agents highly optimistic). In both cases, the oscillations of the optimism degree around 0.5 might be seen or as due both to an overall depression (or rise) of the latter in the market or as caused by agents that are leaving (or joining) the market over that year. Eventually, as reported in Table 6 , the results presented are robust with respect to other variables widely used in the literature as having explanatory power for equity risk premia, namely the Carhart four-factor portfolios. 


\begin{tabular}{ccccccccc} 
Cluster (Year) & $\hat{\alpha}_{g}$ & $\hat{\beta}_{g}$ & $\gamma_{0.5}$ & $\gamma_{0.75}$ & $\gamma_{1}$ & $\gamma_{1.25}$ & $\gamma_{1.5}$ & $\bar{R}^{2}(\%)$ \\
\hline 2012 & $-0.52^{* *}$ & $1.014^{* *}$ & 0.26 & 0.38 & 0.51 & 0.63 & 0.76 & 1.2 \\
2013 & $-0.43^{*}$ & $0.782^{*}$ & 0.11 & 0.24 & 0.36 & 0.49 & 0.61 & 0.6 \\
2014 & $-0.94^{* * *}$ & $1.836^{* * *}$ & 0.48 & 0.60 & 0.73 & 0.85 & 0.98 & 3.7 \\
2015 & $-0.48^{* *}$ & $0.911^{* *}$ & 0.20 & 0.33 & 0.45 & 0.58 & 0.70 & 0.9 \\
2016 & $-1.81^{* * *}$ & $3.435^{* * *}$ & 0.60 & 0.73 & 0.85 & 0.98 & 1.00 & 19.7 \\
\hline Cluster (Year) & $\hat{\alpha}_{g}$ & $\hat{\beta}_{g}$ & $\rho_{0.5}$ & $\rho_{0.75}$ & $\rho_{1}$ & $\rho_{1.25}$ & $\rho_{1.5}$ & $\bar{R}^{2}(\%)$ \\
\hline 2012 & $-0.52^{* *}$ & $1.014^{* *}$ & 0.51 & 0.51 & 0.51 & 0.50 & 0.50 & 1.2 \\
2013 & $-0.43^{*}$ & $0.782^{*}$ & 0.22 & 0.31 & 0.36 & 0.39 & 0.41 & 0.6 \\
2014 & $-0.94^{* * *}$ & $1.836^{* * *}$ & 0.96 & 0.80 & 0.73 & 0.68 & 0.65 & 3.7 \\
2015 & $-0.48^{* *}$ & $0.911^{* *}$ & 0.40 & 0.44 & 0.45 & 0.46 & 0.47 & 0.9 \\
2016 & $-1.81^{* * *}$ & $3.435^{* * *}$ & 1.20 & 0.97 & 0.85 & 0.78 & 0.74 & 19.7 \\
\hline
\end{tabular}

Table 5: U.S. market estimated average degree of optimism for the period 2012-2016. The $\gamma_{i}$ values in the table have been computed by considering that, for large samples and under the assumption of normality of the population, $\bar{\tau} \approx 1 /(\bar{a}-2 \bar{\gamma}+1)$.

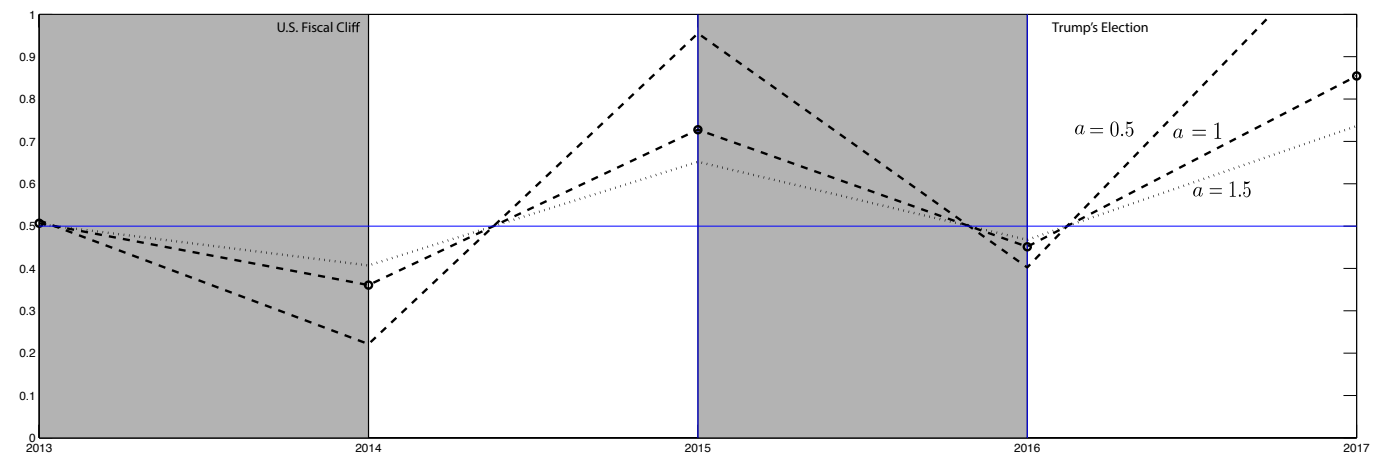

Figure 4: U.S. market estimated average relative degree of optimism for the period 20122016. 


\begin{tabular}{|c|c|c|c|c|c|c|}
\hline Cluster (Year) & $\hat{\alpha_{g}}$ & $\hat{\beta}_{z, t}$ & $\hat{\beta}_{s m b, t}$ & $\hat{\beta}_{h m l, t}$ & $\hat{\beta}_{m o m, t}$ & $\bar{R}^{2}(\%)$ \\
\hline \multirow{3}{*}{2012} & & $0.755^{*}$ & $0.143^{* * *}$ & & & $10.0 \%$ \\
\hline & $-0.20^{*}$ & $0.731^{*}$ & $0.141^{* * *}$ & $0.084^{* * *}$ & & $12.0 \%$ \\
\hline & & 0.395 & $0.096^{* * *}$ & $0.184^{* * *}$ & $-0.319^{* * *}$ & $26.9 \%$ \\
\hline \multirow{3}{*}{2013} & & $0.966^{* *}$ & $0.158^{* * *}$ & & & $5.7 \%$ \\
\hline & $-0.43^{* *}$ & $0.931^{* *}$ & $0.153^{* * *}$ & $0.166^{* * *}$ & & $8.9 \%$ \\
\hline & & $0.895^{* *}$ & $0.050 * * *$ & $0.172^{* * *}$ & -0.0258 & $8.5 \%$ \\
\hline \multirow{3}{*}{2014} & & $1.508^{* *}$ & $0.147^{* * *}$ & & & $8.2 \%$ \\
\hline & $-0.73^{* * *}$ & $1.753^{* * *}$ & $0.099^{* *}$ & $-0.166^{* * *}$ & & $10.4 \%$ \\
\hline & & $1.528^{* * *}$ & 0.069 & -0.015 & $-0.390 * * *$ & $12.8 \%$ \\
\hline \multirow{3}{*}{2015} & & $1.013^{* *}$ & -0.042 & & & $0.9 \%$ \\
\hline & $-0.50 * *$ & $0.974^{* *}$ & -0.045 & -0.020 & & $0.8 \%$ \\
\hline & & $0.951^{* *}$ & -0.048 & $0.095^{*}$ & $-0.300^{* * *}$ & $5.8 \%$ \\
\hline \multirow{3}{*}{2016} & & $3.149^{* * *}$ & $-0.022^{* *}$ & & & $19.9 \%$ \\
\hline & $-1.60 * * *$ & $3.174^{* * *}$ & $-0.081^{* *}$ & 0.018 & & $19.9 \%$ \\
\hline & & $3.015^{* * *}$ & $-0.085^{* *}$ & $0.084^{*}$ & $-0.153^{* * *}$ & $22.1 \%$ \\
\hline
\end{tabular}

Table 6: Results for the robustness test regressions $q_{t, g}=\alpha_{g}+z_{t, g} \beta_{z, g}+S M B_{t, g} \beta_{s m b, g}+$ $H M L_{t, g} \beta_{h m l, g}+M O M_{t, g} \beta_{m o m, g}+u_{g}$, where SMB and HML are the Fama and French mimicking factor portfolios for respectively size and value effects and MOM is the momentum factor mimicking portfolio. 


\section{Conclusions}

In this paper, we have introduced a new approach for modeling optimism that is potentially applicable to a wide range of decision-making models adopted in the literature and which is more analytically tractable compared with other methods proposed so far that make use of probability weighting functions. Moreover, our approach has the advantage of being "market oriented", since the adjustment made is a function of the volatilities of the assets returns under study. The introduction of the latter shows a satisfying consistency with the empirical decision-making literature, allowing even the simplest theories, such as EUT, to describe data concerning seemingly contradictory choice problems that have been treated as paradoxes in the literature, such as that proposed by Allais (1953). Given is simplicity and the relationship between the function introduced and volatility, the model also permits the implementation of agents' degrees of optimism in economic models, such as the extended Grossman model described in Section 4. Our approach has the advantage that a closed form solution can be achieved, something that is usually quite challenging when more complex models, including cumulative prospect theory, are employed in this kind of framework.

In the empirical part of our study, we employ the equilibrium model developed in order to test the significance of the degree of optimism in a financial decision-making problem, and we elicit a market measure for the latter. We have found that optimism indeed seems to matter for agents' expectations regarding market risk premia and, as expected, it seems tied to political and socio-economic events, consistent with the findings of, among others, Benhabib and Spiegel (2017). More complex models involving optimism deserve to be studied in order to obtain not only a more powerful descriptive framework for decision-making problems, but also solutions to puzzling situations in financial economics. 


\section{References}

[1] Mohammed Abdellaoui. Parameter-free elicitation of utility and probability weighting functions. Management Science, 46(11):1497-1512, 2000.

[2] Maurice Allais. Le comportement de l'homme rationnel devant le risque: Critique des postulats et axiomes de l'ecole americaine. Econometrica, 2:503-546, 1953.

[3] Thomas Åstebro, José Mata, and Luís Santos-Pinto. Skewness seeking: risk loving, optimism or overweighting of small probabilities? Theory and Decision, 78(2):189-208, 2015.

[4] Nicholas Barberis and Ming Huang. Stocks as lotteries: The implications of probability weighting for security prices. American Economic Review, 98(5):2066-2100, 2008.

[5] Nicholas Barberis and Wei Xiong. What drives the disposition effect? an analysis of a long-standing preference-based explanation. Journal of Finance, 64(2):751-784, 2009.

[6] Jess Benhabib and Mark M Spiegel. Sentiments and economic activity: Evidence from us states. Economic Journal, 129:715-733, 2017.

[7] Michael H Birnbaum. New paradoxes of risky decision making. Psychological review, 115(2):463, 2008.

[8] Han Bleichrodt and Jose Luis Pinto. A parameter-free elicitation of the probability weighting function in medical decision analysis. Management Science, 46(11):1485-1496, 2000.

[9] Markus K Brunnermeier and Jonathan A Parker. Optimal expectations. American Economic Review, 95(4):1092-1118, 2005.

[10] Ricardo J Caballero. Consumption puzzles and precautionary savings. Journal of Monetary Economics, 25(1):113-136, 1990.

[11] Dan Cao. Speculation and financial wealth distribution under belief heterogeneity. Economic Journal, 128(1):2258-2281, 2017.

[12] Marisa Cenci, Massimiliano Corradini, Alberto Feduzi, and Andrea Gheno. Halffull or half-empty? a model of decision making under risk. Journal of Mathematical Psychology, 68:1-6, 2015. 
[13] John H Cochrane. Asset Pricing:(Revised Edition). Princeton University Press, 2009.

[14] David De Meza and Clive Southey. The borrower's curse: optimism, finance and entrepreneurship. Economic Journal, 106:375-386, 1996.

[15] Darrell Duffie and Larry G Epstein. Stochastic differential utility. Econometrica, 60(2):353-394, 1992.

[16] Larry G Epstein and Stanley E Zin. Substitution, risk aversion, and the temporal behavior of consumption and asset returns: A theoretical framework. Econometrica, 57:937-969, 1989.

[17] Craig R Fox and Russel A Poldrack. Prospect theory and the brain. Neuroeconomics: Decision making and the brain, 145:174, 2009.

[18] R. Craig Fox, Carsten Erner, and J. Daniel Walters. Decision under risk: From the field to the lab and back. In G. Keren and G. Wu (Eds.), Blackwell Handbook of Judgment and Decision Making, Forthcoming.

[19] Thomas A Garrett and Russell S Sobel. Gamblers favor skewness, not risk: Further evidence from united states' lottery games. Economics Letters, 63(1):8590, 1999.

[20] Christian Gollier and Alexander Muermann. Optimal choice and beliefs with ex ante savoring and ex post disappointment. Management Science, 56(8):1272$1284,2010$.

[21] Philip J Grossman and Catherine C Eckel. Loving the long shot: Risk taking with skewed lotteries. Journal of Risk and Uncertainty, 51(3):195-217, 2015.

[22] Sanford Grossman. On the efficiency of competitive stock markets where trades have diverse information. Journal of Finance, 31(2):573-585, 1976.

[23] Sanford J Grossman and Joseph E Stiglitz. On the impossibility of informationally efficient markets. American Economic Review, 70(3):393-408, 1980.

[24] Xue Dong He and Xun Yu Zhou. Portfolio choice under cumulative prospect theory: An analytical treatment. Management Science, 57(2):315-331, 2011.

[25] Brian Hillier. The borrower's curse: comment. Economic Journal, 108(451):1772-1774, 1998. 
[26] G Robert J Hockey, A John Maule, Peter J Clough, and Larissa Bdzola. Effects of negative mood states on risk in everyday decision making. Cognition $\mathfrak{B}^{3}$ Emotion, 14(6):823-855, 2000.

[27] Daniel Kahneman and Amos Tversky. Prospect theory: An analysis of decision under risk. Econometrica, 47(2):263-291, 1979.

[28] Botond Kőszegi and Matthew Rabin. A model of reference-dependent preferences. Quarterly Journal of Economics, 121(4):1133-1165, 2006.

[29] Mordecai Kurz and Maurizio Motolese. Diverse beliefs and time variability of risk premia. Economic Theory, 47(2-3):293-335, 2011.

[30] Albert S Kyle. Continuous auctions and insider trading. Econometrica, 53(6):1315-1335, 1985.

[31] Albert S Kyle. Informed speculation with imperfect competition. Review of Economic Studies, 56(3):317-355, 1989.

[32] Wayne Y Lee, Christine X Jiang, and Daniel C Indro. Stock market volatility, excess returns, and the role of investor sentiment. Journal of Banking $\&$ Finance, 26(12):2277-2299, 2002.

[33] Graham Loomes and Robert Sugden. Regret theory: An alternative theory of rational choice under uncertainty. Economic Journal, 92(368):805-824, 1982.

[34] Rajnish Mehra and Edward C Prescott. The equity premium: A puzzle. Journal of Monetary Economics, 15(2):145-161, 1985.

[35] Drazen Prelec. The probability weighting function. Econometrica, 66(3):497$527,1998$.

[36] John Quiggin. Risk perception and the analysis of risk attitudes. Australian Journal of Agricultural and Resource Economics, 25(2):160-169, 1981.

[37] John Quiggin. A theory of anticipated utility. Journal of Economic Behavior 8 Organization, 3(4):323-343, 1982.

[38] John Quiggin. Comparative statics for rank-dependent expected utility theory. Journal of Risk and Uncertainty, 4(4):339-350, 1991.

[39] John Quiggin. Generalized expected utility theory. The rank dependent model. Kluwer Academic Publisher, 1993. 
[40] Leonard J Savage. The foundations of statistics. Wiley \& Sons, 1954.

[41] Norbert Schwarz. Emotion, cognition, and decision making. Cognition 65 Emotion, 14(4):433-440, 2000.

[42] Herbert A Simon. Models of Man: Social and Rational: Mathematical Essay on Rational Human Behavior in a Social Setting. Wiley \& Sons, 1957.

[43] Herbert A Simon. Bounded rationality and organizational learning. Organization Science, 2(1):125-134, 1991.

[44] Adam Smith. The theory of moral sentiments. 1759.

[45] Chris Starmer. Developments in non-expected utility theory: The hunt for a descriptive theory of choice under risk. Journal of Economic Literature, 38(2):332382,2000 .

[46] Amos Tversky and Craig R Fox. Weighing risk and uncertainty. Psychological Review, 102(2):269, 1995.

[47] Amos Tversky and Daniel Kahneman. Advances in prospect theory: Cumulative representation of uncertainty. Journal of Risk and Uncertainty, 5(4):297-323, 1992.

[48] Peter Wakker and Daniel Deneffe. Eliciting von neumann-morgenstern utilities when probabilities are distorted or unknown. Management Science, 42(8):11311150, 1996.

[49] Peter P Wakker. Testing and characterizing properties of nonadditive measures through violations of the sure-thing principle. Econometrica, 69(4):1039-1059, 2001.

[50] Jiang Wang. A model of competitive stock trading volume. Journal of Political Economy, 102(1):127-68, 1994.

[51] Yaw-Huei Wang, Aneel Keswani, and Stephen J Taylor. The relationships between sentiment, returns and volatility. International Journal of Forecasting, 22(1):109-123, 2006.

[52] Craig S Webb and Horst Zank. Accounting for optimism and pessimism in expected utility. Journal of Mathematical Economics, 47(6):706-717, 2011. 
[53] George Wu and Richard Gonzalez. Curvature of the probability weighting function. Management Science, 42(12):1676-1690, 1996.

[54] George Wu, Jiao Zhang, and Richard Gonzalez. Decision under risk. Blackwell Handbook of Judgment and Decision Making, 399, 2004.

[55] Menahem E Yaari. The dual theory of choice under risk. Econometrica, 55(1):95-115, 1987.

[56] Motohiro Yogo. Asset prices under habit formation and reference-dependent preferences. Journal of Business \&3 Economic Statistics, 26(2):131-143, 2008. 


\section{APPENDIX}

The proofs both of theorem 1 and it's corollary are trivial and are thus omitted.

\section{Proof of proposition 2}

Let us recall that for a normal random variable $w_{i}$ and a constant $a$, the following property applies

$$
\mathbb{E}\left[\exp \left(a w_{i}\right)\right]=\exp \left(\mathbb{E}\left[a w_{i}\right]+\frac{1}{2} \operatorname{VAR}\left[a w_{i}\right]\right)
$$

The expected value function in the maximization problem described in equations (12) and (13) takes an explicit form, being $w_{i}$ Gaussian with mean $\left(m_{i}+p z_{i}\right) r+x\left(\mu_{v}-p r\right)$ and variance $\sigma_{v}^{2} x^{2}$ as follows

$$
V_{*}\left(w_{i}\right)=-2\left[1-\phi\left(\gamma_{i}, \sigma_{w}\right)\right]\left[\exp \left(-a_{i}\left(\left(m_{i}+p z_{i}\right) r+x\left(\mu_{v}-p r\right)+\frac{a_{i}^{2}}{2} x^{2} \sigma_{v}^{2}\right)\right)\right]
$$

where

$$
\phi\left(\lambda, \sigma_{x}^{2}\right)=\left\{\begin{array}{lll}
1-\frac{1}{2} \exp \left\{-a\left(\gamma-\frac{1}{2}\right) \sigma_{x}^{2}\right\} & \text { if } \quad \frac{1}{2} \leq \gamma<1 \\
0 \quad \text { if } & 0<\gamma<\frac{1}{2}, \sigma_{x}^{2} \geq \sigma_{*}^{2} \\
1-\frac{1}{2} \exp \left\{-a\left(\gamma-\frac{1}{2}\right) \sigma_{x}^{2}\right\} & \text { if } \quad 0<\gamma<\frac{1}{2}, \sigma_{x}^{2}<\sigma_{*}^{2}
\end{array}\right.
$$

and where, differently from equation (7), the indicator function has been expressed explicitly.

For simplicity, we split the proof into three parts by dividing the cases in which $\gamma_{i}$ assumes respectively values greater and lower than $1 / 2$ and in which the limiting variance is exceeded.

CASE 1: $\frac{1}{2} \leq \gamma<1$

Starting from the case in which $\frac{1}{2} \leq \gamma<1$, equation (A) can be rewritten, by substituting $\phi\left(\gamma_{i}, \sigma_{v}\right)$ according to equation (B), as

$$
-\left[\exp \left\{-a_{i}\left(\gamma_{i}-\frac{1}{2}\right) \sigma_{v}^{2} x^{2}\right]\left[\exp \left(-a_{i}\left(\left(m_{i}+p z_{i}\right) r+x\left(\mu_{v}-p r\right)+\frac{a_{i}^{2}}{2} x^{2} \sigma_{v}^{2}\right)\right)\right]\right.
$$

which is the same as

$$
-\left[\exp \left(-a_{i}\left(\left(m_{i}+p z_{i}\right) r+x\left(\mu_{v}-p r\right)+a_{i}\left(\frac{a_{i}+2 \gamma_{i}-1}{2}\right) x^{2} \sigma_{v}^{2}\right)\right)\right]
$$

The first order condition is given by

$$
a_{i}\left[\left(\mu_{v}-p r\right)-\left(a_{i}-2 \gamma_{i}+1\right) x \sigma_{v}^{2}\right] \exp \left(-a_{i}\left(x\left(\mu_{v}-p r\right)+a_{i}\left(\frac{a_{i}+2 \gamma_{i}-1}{2}\right) x^{2} \sigma_{v}^{2}\right)\right)=0
$$

The exponential term is always positive so that the first order condition (f.o.c.) is solved for

$$
x_{1}^{*}=\frac{\mu_{v}-p r}{\sigma_{v}^{2}\left(a_{i}-2 \gamma_{i}+1\right)}
$$


which is a global maximum being the f.o.c $>0$ for $x<x_{1}^{*}$ and $<0$ for $x>x_{1}^{*}$.

CASE 2: $0<\gamma<\frac{1}{2}, \sigma_{x}^{2}<\sigma_{*}^{2}$

The solution for this case, where the optimism weighting function is the same as above, follows exactly the same process represented in Case 1 , and gives the same solution so that $x_{2}^{*}=x_{1}^{*}$, which is a maximum for the same consideration given in the previous case.

CASE 3: $0<\gamma<\frac{1}{2}, \sigma_{w}^{2}>\sigma_{*}^{2}$,

The solution for this case is trivial, and in fact we have that, according to equation (B), $\phi\left(\gamma_{i}, \sigma_{w}\right)=0$ so that equation (A) becomes

$$
-2\left[\exp \left(-a_{i}\left(\left(m_{i}+p z_{i}\right) r+x\left(\mu_{v}-p r\right)+\frac{a_{i}^{2}}{2} x^{2} \sigma_{v}^{2}\right)\right)\right]
$$

and by equating the f.o.c. to zero.

$$
x_{3}^{*}\left(\sigma_{*}^{2}\right)=\frac{\mu_{v}-p r}{\sigma_{v}^{2}\left(a_{i}\right)}
$$

which turns equal to zero by assumption (7). Again, this is a global maximum being the f.o.c $>0$ for $x<x_{3}^{*}$ and $<0$ for $x>x_{3}^{*}$.

Eventually, by collecting both of the relevant cases (Cases 1 and 2), we end up with

$$
x_{i}=\frac{\mu_{v}-p r}{\sigma_{v}^{2}\left(a_{i}-2 \gamma_{i}+1\right)}
$$

which is the first result in Proposition 2.

Finally, in order to determine the equilibrium price, we make use of the equilibrium condition

$$
\sum_{i=1}^{n} x_{i}=\sum_{i=1}^{n}\left[\frac{\mu_{v}-p r}{\sigma_{v}^{2}\left(a_{i}-2 \gamma_{i}+1\right)}\right]=\sum_{i=1}^{n} z_{i}+z_{0}
$$

By extracting the terms which are independents from the summations and dividing both sides by $n$, we have

$$
\left[\frac{\mu_{v}-p r}{\sigma_{v}^{2}}\right] \frac{1}{n} \sum_{i=1}^{n}\left[\frac{1}{\left(a_{i}-2 \gamma_{i}+1\right)}\right]=\frac{1}{n} \sum_{i=1}^{n} z_{i}+z_{0}
$$

Thus, by using the same notation used in Section 3, we have

$$
\left[\frac{\mu_{v}-p r}{\sigma_{v}^{2}}\right] \bar{\tau}=z
$$

and eventually

$$
p=\frac{1}{r}\left(\mu_{v}-\frac{z \sigma_{v}^{2}}{\bar{\tau}}\right)
$$

which is the final result in Proposition 2. 